\title{
Face to Face with Anti-Muslim Sentiment: A Qualitative Study into the Coping Mechanisms of Young College and University Muslim Students and Graduates in Flanders
}

\author{
Ans De Nolf ${ }^{1, *(D)}$, Leen $d^{\prime}$ Haenens ${ }^{1}(\mathbb{D})$ and Abdelwahed Mekki-Berrada ${ }^{2}(\mathbb{D}$ \\ 1 Institute for Media Studies, KU Leuven, 3000 Leuven, Belgium; leen.dhaenens@kuleuven.be \\ 2 Departement of Anthropology, Laval University, Quebec, QC G1V 0A6, Canada; amb@ant.ulaval.ca \\ * Correspondence: ans.denolf@kuleuven.be
}

Citation: De Nolf, Ans, Leen d'Haenens, and Abdelwahed Mekki-Berrada. 2021. Face to Face with Anti-Muslim Sentiment: A Qualitative Study into the Coping Mechanisms of Young College and University Muslim Students and Graduates in Flanders. Religions 12: 135. https://doi.org/10.3390/ rel12020135

Received: 6 January 2021

Accepted: 15 February 2021

Published: 20 February 2021

Publisher's Note: MDPI stays neutral with regard to jurisdictional claims in published maps and institutional affiliations.

Copyright: (c) 2021 by the authors. Licensee MDPI, Basel, Switzerland. This article is an open access article distributed under the terms and conditions of the Creative Commons Attribution (CC BY) license (https:// creativecommons.org/licenses/by/ $4.0 /)$.

\begin{abstract}
This explorative study seeks to provide insights into the ways young Muslim adults experience and cope with Islamophobia in Flanders. For this purpose, in-depth interviews with 14 Muslims aged 19 to 33 were conducted in the spring of 2020. Our interviewees defined themselves as Muslims and all had been confronted with racism or anti-Muslim sentiment in their daily life. Depending on reported intentions, we identified seven coping strategies in the face of such sentiment: relativization, avoidance, communication, oppression, conciliation, reaction and passive coping strategies. These forms of coping are not mutually exclusive. They are often used in combination, and they may be interchangeable in some situations. This study seeks to complement and deepen the existing literature on anti-Muslim sentiment in Flanders. Its findings should be considered as a starting point for further deductive testing of the identified typologies, meant to inspire follow-up research and serve as evidence for future policymaking.
\end{abstract}

Keywords: anti-Muslim sentiment; anti-Muslim prejudice; racism; Islamophobia; coping with antiMuslim sentiment; Muslim young adults; Flanders

«It is their country» (Yara, 19 years old)

\section{Introduction}

\subsection{The Context of the Research}

Belgium has a long history of using migrant labourers and Flanders-its Dutchlanguage Northern region-is no exception. As a result, the country is host to culturally diverse people (e.g., d'Haenens et al. 2019). For instance, Muslims make up about 5 to 6 percent of the Flemish population (Hertogen 2017; Pew Research Center 2017) and around 8 percent of the Belgian population, a number that is expected to reach 15 percent by 2050 (e.g., Pew Research Center 2017).

This growth has been accompanied by increased public and media interest-an interest that can in part be described as negative-with Islam often being presented as a uniform, global superpower which negates the individuality of its believers (Martín-Muñoz 2010). It can also be stigmatizing and discriminating, painting a picture of Muslims as angry and lazy people, stripped of individual traits and a threat to social security (Aziz 2017). Furthermore, any socio-economic difficulties that Muslims experience are interpreted as a result of their religion or their possible foreign descent (Zemni 2011).

The news media in Flanders tend to portray Muslims as a homogenous group that stands in direct opposition with the "mainstream Flemish population" (De Ridder 2010). When portrayed in the Flemish media, Muslims are implicitly or explicitly linked with negative themes such as terrorism and fundamentalism, and Islam is mainly framed as a threat (Ichau and d'Haenens 2016; Zemni 2011). A number of political parties are keen to spread this one-sided negative othering rhetoric of Muslims being in direct opposition with the "mainstream Flemish population", along with "solutions to the Muslim problem" such 
as the ban of Islamic headscarves in public schools and in the workplace (Aziz 2012; Lean 2017; Zemni 2011). This reductionist, “Us vs. Them" image of Muslims-Western society and its unimpeachable norms and values versus "Muslims" and their "alien" valuesresults in a perception of Muslims as persons who are foreign, inferior, dominated by fanaticism, fundamentalism and irrationality and thus Islam is seen as a threat to the values of non-Muslim societies (Martín-Muñoz 2010; Mekki-Berrada 2019), as the root cause of social and political issues and even as "our country's biggest problem" (Zemni 2009, p. 10). This negative public perception in the debate on Islam has moved to the centre of political and societal discussions since the 1980s with the electoral rise of the far-right party "Flemish Block" and is still very much ongoing (Rahbari 2020; Zemni 2011).

Just as there is no single Islamic movement, there is no single cause of anti-Muslim sentiment nor any single victim of it, the sentiment is directed against Muslims at large (De Koning 2019). The "Muslim" label is less based on specific religious elements than on external features such as language (Arabic), clothing, or the presence of a beard (De Koning 2019). Islam is thus treated as a "race" based on specific identifiers (Zemni 2009).

Anti-Muslim sentiment such as fear, hatred, or prejudice towards (perceived) Muslims can have an enormous impact on the groups it targets (Lean 2017): discrimination, unfair treatment at the hand of the justice system, social exclusion, a lack of protection of fundamental rights and violent hate crimes (Martín-Muñoz 2010; Mekki-Berrada 2019). Yet, it receives little recognition worldwide (Martín-Muñoz 2010). The central focus in social debates and in academic research is often the problematization of Islamic culture rather than the underlying reasons for this problematization and the way Muslims experience it. The social debate about Muslims is usually held without the participation of this minority group, whose voice is also rarely heard in academic research (Kundnani 2014). This study aims to remedy this, letting Flemish Muslims answer in their own words a very simple, twofold question: how do they experience anti-Muslim prejudice, and how do they cope with it? We have asked this question to young college and university Muslim students and graduates in Flanders. The present article reports their answers and discusses them.

\subsection{Islamophobia and Coping Mechanisms}

According to anthropologist Martijn DeJonckheere and Vaughn (2019, p. 26), Islamophobia is a "set of prejudices, stereotypes, and discrimination that Muslims face because of a one-sided, negative and stigmatizing interpretation of their religious tradition". Moreover, it refers to a "fear of and hostility toward Muslims and Islam, as well as the discriminatory, exclusionary, and violent practices arising from these attitudes that target Muslims and those perceived as Muslims" (Green 2019, p. 1). This can translate into a public discourse about Islam that centres on fear, hatred, and prejudice.

In current academic research, but also in the public discourse, Islamophobia functions as an umbrella term to reflect the variety of stigmas and antagonisms towards Muslims worldwide (Sayyid and Vakil 2010; Kunst et al. 2013). These stigmas can be inherently religious but can also find their roots in ethnic or cultural characteristics (Taras 2013). In other words, anti-Muslim sentiment is not only based on religion, although it is often portrayed as such in the public and academic discourse (Taras 2013). The framework of this research builds on De Koning's (2019) definition of Islamophobia, a controversial term. It is suggested for instance that it might undermine the recognition of a possible threat-but above all, many view it as an Islamist weapon deployed to silence criticism of Islam as a human construct, with the active support of lazy thinkers in intellectual and journalistic circles. More anecdotally, some fear it might become a euphemism for "hatred", thus normalizing xenophobic statements (Spruyt and Elchardus 2012). Other names for this phenomenon were suggested as a solution, such as "anti-Muslimism" by Fred Halliday (1999) because of its ideological nature, or "anti-Muslim racism" by James Carr because of its racist nature and proximity to anti-semitism (Carr 2018), yet Islamophobia remains the most potent term. This study, while recognizing the controversy surrounding the term, argues that Islamophobia is an under-researched phenomenon with enormous 
consequences at the individual and community level such as social exclusion, intrusive government surveillance, profiling programs, detentions and deportations, hate crimes and a lack of protection of fundamental rights for its victims (Green 2019; Martín-Muñoz 2010). Islamophobia has kept increasing over the last decade, and although it affects all individuals, it has a significant gendered dimension: women who are presumed to be Muslim face disproportionately more consequences of this phenomenon (Easat-Daas 2019).

How a person deals with this discrimination, contempt, racism and in short Islamophobia or anti-Muslim sentiment affects both her or his physical and mental health (Brondolo et al. 2003; Fischer and Shaw 1999; Williams et al. 2003). The following is an overview of the literature that addresses different ways in which people deal with the prejudices, stereotypes and discrimination that make up anti-Muslim sentiment.

Lazarus and Folkman (1984) define an individual's efforts to overcome, reduce, or deal with certain stressful and emotional situations as "coping mechanisms" (Vrancken 2017). Based on a systematic literature review, Jurriaan Omlo (2015) proposes the following fourfold coping typology in the face of anti-migrant and anti-Muslim sentiment, labelled after their supposed effect: polarizing strategies, avoiding strategies, conforming strategies and finally, connecting strategies. It is important to note that the use of these strategies depends on personal characteristics as well as social factors and circumstances (CTID Het Collectief tegen Islamofobie en Discriminatie; Foner and Alba 2008; Omlo 2015).

The first strategy identified by Omlo (2015) is the polarizing strategy. This implies that a person who is being discriminated against entirely attributes the cause of this discrimination to his or her victimizer, not letting the aggression get to her $/ \mathrm{him}$. This is an effective strategy to both protect one's self-confidence and to alleviate the stress and emotional tensions caused by discrimination (CTID Het Collectief tegen Islamofobie en Discriminatie). However, it also has negative consequences, fostering hostility, distrust, and disregard for common interests (Omlo 2015). Research by Bloom et al. (2019) and Field (2007) shows that the apparent lack of integration of Muslim minorities largely prevents Muslims from identifying with their Western nationality. This apparent lack of integration is often attributed in the public debate to an inability/reluctance to integrate, with little attention being paid to social circumstances, such as religious stigma and antiMuslim sentiment (Jasinskaja-Lathi et al. 2008). People faced with anti-Muslim sentiment feel rejected and tend to withdraw from society instead of striving to integrate into the mainstream (Aziza 2015; Jasinskaja-Lathi et al. 2008). This reduced sense of belonging can lead to an increase in negative emotions such as anger, guilt, and shame, which in turn can lead to burnout, depression, and psychosomatic ailments (CTID Het Collectief tegen Islamofobie en Discriminatie).

A second strategy described by Omlo (2015) is avoidance: after experiencing discrimination, prejudice, or stereotypes, a person will socially and/or physically distance herself/himself from specific relationships, situations, or domains (Major and O'Brien 2005; Omlo 2015; Najib and Hopkins 2019). This can be done by avoiding completely—or as much as possible-locations where discrimination has been observed or experienced, by psychologically devaluing situations and places where discrimination occurs, or by denying racism as it is being experienced. Such denial or reticence in naming discrimination is the most common coping strategy of people faced with discrimination. Omlo (2015) adds that recognizing discrimination for what it is can also have a social impact as it involves the notion of guilt.

Denial of the discrimination one is experiencing tends to trivialize the resulting stigmainduced situations (Major et al. 2002). If the experience of such adverse situations is not attributed to stigma, the victim may look for their cause within himself/herself or focus on external factors, as a result of which the aspect of discrimination becomes less visible (Major et al. 2002). This denial can lead to doubts about the occurrence of discrimination, possibly resulting in social isolation or psychological stress (Omlo 2015).

The third coping category described by Omlo (2015) refers to forms of conformism intended to reduce the risk of discrimination and social exclusion-displaying one's com- 
pliance with the perceived norm. Within this strategy, also described by Najib and Hopkins (2019), racism is seen as something that can be remedied by investing heavily in social relationships so as to prove oneself socially and professionally, with a strong focus on helpfulness and friendliness (Steele et al. 2002). A far-reaching variant of this coping strategy is the rejection or abandonment of one's own "cultural identity" or "roots" - completely or limited to the public sphere (Branscombe et al. 1999). Such a coping strategy can limit feelings of helplessness, facilitate upward mobility and reduce stress. One downside is that it can blind one to actual acts of discrimination, or persuade the victim they are at fault for refusing to adjust (Omlo 2015). It can also be psychologically burdensome, alienating persons from their cultural group or "roots," in some cases leading them to adopt discriminatory behaviours (Omlo 2015). Such alienation from a close-knit, inward-looking group can lead to loneliness, insecurity, social isolation, and even, in extreme cases, an increased risk of schizophrenia (Omlo 2015).

Omlo's fourth coping strategy is a "connecting strategy" - that is, actively striving to dispel the stigmas and prejudices attached to one's culture of origin: putting things into perspective, focusing on common characteristics rather than cultural differences in order for group boundaries to become blurred, displaying an understanding of the situation and the victimizer and attempting to have a constructive conversation with the latter (Heatherton 2003). This can take place at an individual as well as a collective level, with groups addressing the issues of stigma and discrimination through social and political actions (Omlo 2015). This strategy can lead to increased resilience, constructive action in the face of discrimination, and a reduced sense of helplessness. It can also lead to disappointment and anger if the discriminated group's need for inclusion is not adequately addressed (Omlo 2015).

Aziza (2015) defines two more coping strategies. One is best described as a "relativizing" strategy, which involves finding comfort and guidance in religion: the purported connection with the divinity may help control and process negative emotions (Aziza 2015). This can help a person cope with stress and social isolation so that in the long run they will feel more at home in the society that was initially at the root of their anxiety and social isolation (Verkuyten and Yildiz 2007). Of course, it may also reinforce a siege mentality, black and white thinking and social fragmentation and, in circumstances such as the post-9/11 "war on terror", religiosity, in addition to being a protective factor, could also have an ad hoc negative impact on mental health and wellbeing (Rousseau et al. 2013).

Aziza's other coping strategy can be described as "communicative". This involves seeking counselling from support organizations, professional help from a psychologist or psychiatrist skilled in multicultural matters, etc. (Aziza 2015). Discussing the situation with a professional counsellor, a support group, or friends and family can reduce feelings of helplessness and increase the chances of implementing an appropriate combination of coping mechanisms (Omlo 2015).

Omlo (2015) himself points out that combining coping mechanisms is the most effective way to limit the negative impact of discrimination. Of course, the mechanisms chosen will vary from one person and context to the next (Kunst et al. 2012).

Omlo and Aziza's typologies function as a theoretical background for this study, which is based on the descriptions and discussion of the experiences and coping mechanisms of young adult Flemish Muslims, in their own words.

\section{Materials and Methods}

\subsection{Participants}

This study explores the experiences and coping strategies of Muslim youth (aged 19 to 33) living in Flanders. Participants' ethical approval was granted by the Research Ethics Board of Laval University ${ }^{1}$. Individuals invited to participate in the study had to be at least 18 years old and self-identify as Muslims. They were approached through

1 Approval No. 2019-155/29-07-2019. 
targeted snowball sampling based on both the personal network of the researcher and the networks of the potential respondents. An equal amount of men and women were included in the study. In order to keep diversity among the studied population as broad as possible, other characteristics were specified such as place of residence (urban, rural), creed (strictly practicing, practicing, not practicing), migration background (different countries of origin), and choice of Islam (born into the faith or convert). Our informants include first, second, and third-generation migrants (see Table 1). They were still students or had already graduated, holding a higher education degree.

Table 1. Overview of our informants ${ }^{2}$.

\begin{tabular}{|c|c|c|c|c|c|c|c|c|}
\hline Name & Age & Gender & Residence & Country of Birth & $\begin{array}{c}\text { Country of Birth } \\
\text { Parents }\end{array}$ & $\begin{array}{c}\text { Educational } \\
\text { Level }\end{array}$ & $\begin{array}{l}\text { Current Status } \\
\text { in Belgium }\end{array}$ & $\begin{array}{c}\text { Strictness of } \\
\text { Creed }\end{array}$ \\
\hline Emir & 23 & M & Urban & Iraq & Iraq & University* & Residence permit & Strict \\
\hline Meyra & 22 & $\mathrm{~F}$ & Rural & Belgium & Turkey & College * & Dual nationality & Practicing \\
\hline Layla & 21 & F & Urban & Belgium & Morocco & University * & $\begin{array}{c}\text { Belgian } \\
\text { nationality }\end{array}$ & Strict \\
\hline Malik & 24 & M & Urban & Iran & Afghanistan & University & $\begin{array}{c}\text { Belgian } \\
\text { nationality }\end{array}$ & Practicing \\
\hline Musa & 24 & M & Rural & Belgium & Morocco & College * & Dual nationality & Practicing \\
\hline Driss & 24 & M & Urban & Iraq & Iraq & College * & Dual nationality & Not Practicing \\
\hline Yannick & 23 & M & Urban & Belgium & Morocco & College * & Dual nationality & Practicing \\
\hline Berat & 22 & $\mathrm{M}$ & Urban & Belgium & Morocco & College & Dual nationality & Practicing \\
\hline Noor & 19 & $F$ & Rural & Belgium & Tunisia \& Belgium & College* & Dual nationality & Strict \\
\hline Yara & 19 & $\mathrm{~F}$ & Rural & Belgium & Turkey & College * & Dual nationality & Practicing \\
\hline Fatma & 24 & $\mathrm{~F}$ & Rural & Belgium & Tunisia & College * & Dual nationality & Not Practicing \\
\hline Ines & 26 & F & Urban & Belgium & Turkey & University * & Dual nationality & Practicing \\
\hline Ozan & 33 & $\mathrm{M}$ & Urban & Iraq & Iraq & University & Refugee & Strict \\
\hline Ziara & 22 & F & Rural & Belgium & Morocco \& Belgium & University * & $\begin{array}{c}\text { Belgian } \\
\text { nationality }\end{array}$ & Practicing \\
\hline
\end{tabular}

\subsection{Interview}

To be able to perform a thematic analysis, we opted for semi-structured, in-depth interviews in the language preferred by the informants (English or Dutch) so that they felt free to speak openly ${ }^{3}$. The key interview questions can be found in Table 2.

Table 2. Core interview questions (overview).

\begin{tabular}{l}
\hline Do you define yourself as a Muslim? \\
\hline What does it mean for you to be a Muslim? \\
\hline How do you think the media represent Islam and Muslims? \\
\hline Some people say that Muslims are discriminated against, others say they are not: what do you \\
think? \\
\hline If you are a victim of hatred, discrimination or other violence because you are a Muslim, how do \\
you deal with it? \\
\hline If you needed to talk about it, whom would you turn to, and where? \\
\hline Do you know any organizations/associations that help people faced with anti-Muslim sentiment?
\end{tabular}

2 The names of the informants have been replaced with pseudonyms to protect their identity.

3 The questions in this article stem from the interview guide used in an on-going, broader international research project: "Islamophobia in Scholarship and the Media: A Cross-National Study of Discourses and their Impact" led by the third author, Abdelwahed Mekki-Berrada, Laval University, Quebec, Canada, and funded by the Social Sciences and Humanities Research Council of Canada (SSHRC \# 890-2018-0016; 2019-2024). 
The semi-structured interview method provides the means to collect open-ended data on the experiences, thoughts, feelings and beliefs of the informants. Individual in-depth interviews provide the possibility to discuss more personal, social and sensitive issues such as Islamophobia (DiCicco-Bloom and Crabtree 2006; DeJonckheere and Vaughn 2019). Hence, semi-structured, in-depth interviews provided additional iterative possibilities, allowing informants to express themselves and giving the interviewer the freedom to ask further questions (Savin-Baden and Major 2013).

Such an approach made it possible to discuss and analyze the experiences, meanings and emotions of young Muslims in the face of anti-Muslim sentiment (Boeije 2014). We opted for a phenomenographic research design, a qualitative research approach designed to investigate different ways of experiencing and thinking (Marton 1986) to discover how Muslim youth experience and deal with this phenomenon. Phenomenography makes it possible to empirically study societal phenomena and aspects, to understand, interpret and even to experience them (Savin-Baden and Major 2013). By opting for semi-structured interviews, the notion of internal validity concerns the core questions of the interview as well as the way in which the interview was conducted (Kuzmanić 2009). When interviewing, the researcher repeated parts of the answers back to the informants to validate the researcher's understanding of their experience and to remain as reflexive as possible (Palaganas et al. 2017). In addition to this approach, the researcher attempted to limit her possible "weight" on the informants' answers by asking core questions that avoided steering in a particular direction, and by keeping an open and positive attitude towards the informants, regardless of their answers.

In March and April 2020 the interviews were conducted by telephone and video call, owing to the full lockdown measures in place during the first wave of the Covid-19 crisis. The semi-structured in-depth interviews were recorded and transcribed with the consent of each informant. During the transcription process, the names of the informants were changed and specific place names were omitted to ensure confidentiality.

\subsection{Data Analysis}

The aim of the study was to develop a typology of coping strategies based on systematically gathered and analyzed data. The interview transcripts were encoded with NVivo to perform a thematic analysis. The sensitizing concepts, chosen on the basis of our research objective, the literature and the transcribed interviews, formed the "common thread" of the research (Hoonaard 1997). These concepts contributed to five major themes that were contextualized in the analysis of the transcripts: demographics, experiencing anti-Muslim sentiment, causes of anti-Muslim sentiment, coping mechanisms for anti-Muslim sentiment and solutions for anti-Muslim sentiment. The creation of such a code tree was the result of an iterative process intended to determine which codes could bring meaningful answers to our interview questions. The coding process consisted of a mixed coding approach. First, open coding was performed, after which the open codes were merged through axial coding into broader categories related to each other (Roose 2017). Finally, selective coding was performed, in which the different categories were linked to each other (Roose 2017). This inductive coding was enriched with a deductive approach, whereby the added codes were grounded in the literature. These codes can be found in Appendix A: Overview of coded themes.

\section{Findings and Discussion}

The findings are presented as much as possible in the informants' own words, giving voice to the perceptions and experiences of young Muslim adults.

"When we say the word Islam, most of the people get the ISIS bell ringing or the jihad bell ringing or you know, get the burqa bell ringing." (Emir, 23)

All 14 informants, without exception, mentioned various prejudices and stereotypes associated with Muslims and Islam. For instance, they felt condemned purely on the basis of their appearance. They did not feel welcome in Belgium and thought they faced 
stigma and prejudice. They felt they were viewed as antagonistic to Belgian culture, that mainstream Belgians saw things through a simple "Us vs. Them" lens, and that in the "Us" group there was no place for them because they were seen as "deviant from the norm". As a result, they felt rejected by society.

"You notice that people look at you differently." (Musa, 24)

"On the street, they look at you like ... it's the strangest thing because I did not do anything wrong and yet people look at me like I wrecked this society." (Noor, 19)

"We are in this phase where you can choose anything: gender, ideas, ideologies, ... you can choose anything but Islam." (Ozan, 33)

Such prejudices and stereotypes are not without consequences. For example, discrimination, racism and even violence were discussed extensively within the context of Belgian society.

"Racism that's ... we-we really live it, it is out of control. If there's one thing people can't stand, it's Muslims." (Meyra, 22)

The respondents indicated that anti-Muslim sentiment is mediated by various factors, such as the victimizer's place of residence. They believe that anti-Muslim prejudice is related to (a lack of) positive contact between Muslims and non-Muslims. According to the interviewees, people living in a small town or village with little demographic diversity will tend to be more strongly influenced by prejudices and stereotypes about Muslims.

The age of the victimizer also comes into play. For instance, it was pointed out that anti-Muslim sentiment mostly comes from the "older" generation-age groups of 40, 50 and 60 were cited.

In addition to the victimizer's characteristics, aspects such as religious signs or ethnicity of the victim also play a role. Informants stated that Muslim women wearing a headscarf were confronted with a huge increase in anti-Muslim sentiment. Some saw this as proof of increasing hostility towards Muslim women, which is in line with the findings of Easat-Daas (2019), that Islamophobia has a gendered dimension. However, the opposite claim was also made: Fatma claimed that her younger brother experienced more hostility than she did because of his typical Arabic appearance, which made him look more "dangerous" and "criminal". When looking at the incidence of Islamophobia, the literature showed a greater emphasis on the cultural aspects of Islam, more, in particular, the religion itself, than what emerged from our findings, where the emphasis lies more on appearance, on "looking like a Muslim".

\subsection{Coping Mechanisms}

The literature describes six different coping strategies, namely polarizing, avoiding, conforming, connecting, relativizing and communicative strategies. These largely correspond to the typology of strategies that emerged from the interviews in this study. In the literature, however, the emphasis lies on the outcomes of certain coping strategies, while in this study the focus is on the rationales behind the different coping mechanisms chosen by the informants. This way, an insight is provided into the intentions of the young Muslim adults, because the outcomes are not always in line with their rationales and this insight can help mental health professionals adequately support them when coping with anti-Muslim sentiment.

Moreover, young Muslim adults facing anti-Muslim sentiment in Flanders resort to both active and passive coping mechanisms. Putting such an experience into perspective turned out to be the most common strategy: either minimizing the experience or displaying understanding for the victimizer.

\subsubsection{Conciliation}

The most used strategy, with twelve mentions, is the strategy of conciliation, which consists of displaying understanding for their victimizers and trying to remain calm, friendly and understanding at all costs. 
"Maybe he's been through something bad. I don't know him, so maybe he was beaten or scolded by a person of foreign origin, or something ... " (Ozan, 33)

"I don't want to be rude to people who do racist things. If someone looks down on me, then I can't be that angry or against that person. I'm not negative at all, because I also think something like 'okay, that's also a human being' and, eh ... you have to understand what that human being thinks.'" (Yara, 19)

"I don't see it as bad; I just see it as a sign of ignorance." (Layla, 21)

In the conciliation coping strategy, the media and the respondents' educational status are also used to avoid blaming and responding violently to racist aggressors: "But that's not his fault either, I realize that because I am highly educated, because I know that he is unconsciously influenced by the media." (Ozan, 33)

\subsubsection{Communication}

A further active coping strategy that was mentioned by ten informants has to do with "communication": discussing their experience of racism and anti-Muslim sentiment with their family members, peers, friends or partner to get the emotions "off their chest" and eventually overcome the negative experience. Emir indicated that he could go to the Imam of his mosque for this.

"Whenever we have problems or worries that need to be solved, we go to these imams and talk to them a lot about our problems and then they give us advice." (Emir, 23)

Such a statement points to the fact that open-minded Imams could be solicited to be involved in some intervention programs (Abu-Ras et al. 2008; Mekki-Berrada and Schensul 2018).

\subsubsection{Putting Things into Perspective}

Another prominent active coping strategy that emerged in eight of our interviews was the "relativizing" strategy, with interviewees insisting that it was "not that bad" after all and that Belgian society also had many positive sides. They strive to look at "the bigger picture", downplaying their personal experiences of anti-Muslim sentiment.

"There needs to be a bit of bitterness so you can feel the sweetness, and so I just don't really care about it." (Emir, 23)

A specific relativizing strategy is the use of humour to defuse dark situations.

"If you're going to work somewhere, or you're going to be in a new class or whatever... It's always amusing how people think most Muslims can't speak Dutch. I always think that's funny. Most people just immediately speak English to me or ask 'Can you speak Dutch?' and then I say 'Yeah I can speak Dutch'. Sometimes, I like to play a little game with these people, then I say 'Eh .. D . . D . . Dutch?'" (Yannick, 23)

Another way of putting things into perspective is to use the Islamic faith as a guide. Finding reassurance and trust in their faith lessens the informants' perception of hostile behaviours. Faith puts everything into perspective for young Muslim adults and they draw support from it.

"You find comfort in being a Muslim because Islam is so diverse and it means a lot to me." (Malik, 24)

"According to the Koran, every human being is a sinner, so everyone will do something wrong, be it deliberately or unconsciously." (Noor, 19)

\subsubsection{Suppression}

Another active coping strategy, referred to six times during the interviews, consisted of suppressing a psychological or physical experience of anti-Muslim sentiment. While our informants view such experiences as negative, they refrain to mention them as such to the outside world, or sometimes even to themselves. One way of doing this is to suppress signs showing to the outside world that hostility gets to them. 
"I never show that it broke me or anything like that." (Ines, 26)

"Once, on the bus, I really had to fight to hold back the tears." (Yara, 19)

Another way consists in actively denying any mental suffering, both to others and to oneself.

"We didn't want to let that come to our hearts. But it did." (Fatma, 24)

"I tell myself that it doesn't matter, but I am a very sensitive person, and I am going to think about it for weeks (... ). I give myself a pep talk, but at the end of the day I still feel it." (Noor, 19)

Negative experiences can also be ignored in such a way that they end up utterly forgotten. Only in very specific situations-an interview, for instance-are such experiences brought back to mind.

"A boy asked me if I had experienced anything racist myself, and I said 'No, not really', until all of a sudden I thought 'but actually you've experienced something, but you've hidden it so deeply that it took time to recall it.'" (Ines, 26)

\subsubsection{Reaction}

Negative experiences can encourage young Muslim adults to adopt certain behaviours and patterns of thought. For the purposes of this study, such a response is defined as "reactive coping" and was mentioned six times during the interviews. The behaviours and thinking patterns within these coping strategies can have various expressions but are each a direct result of the experience. One reactive coping strategy is to enter into a dialogue with the victimizer. In this process, the Muslim youngster attempts to start a conversation with the person who displayed an anti-Muslim prejudice and addresses his or her behaviour.

"In my opinion dialogue is the best option. I think there are far too few people who actually try to talk. The biggest problems that actually involve discrimination are a result of a lack of communication between the two sides." (Berat, 22)

While noting that it is not easy to enter into a dialogue with the victimizer, the informants did recognize the value of this approach.

An additional reactive coping strategy is more structured action. For example, in her quest for solutions, Fatma told us that she was working on a project intended to address the prejudices of the executive power, for example, the police force, in relation to minority groups. Another example is Ines, who has become a member of an independent organization dedicated to Muslim youth. Meyra is also involved in an organization that advises young Muslim women on education, careers, and women's issues. Another form of action is lodging a complaint with Unia, the Interfederal Equal Opportunities Center, which is exactly what Noor did after being confronted with anti-Muslim prejudice when on a student job.

A different reactive coping strategy is to devalue the victimizer, as the quote below illustrates:

"You tell yourself they're not worth it - they're not worth having an argument with."

(Berat, 22)

Another, more reactive strategy consists in trying to prove the victimizers wrong by not conforming to the prevailing stereotypes (behaving dangerously, disdaining Belgian society and culture, etc.).

"You don't have to say anything in return, that's not my goal at all, I just want to be able to show in my behaviour that I'm not such a person at all (... ), I just want to refute stereotypes with my behaviour". (Yara, 19)

\subsubsection{Avoidance}

A less prominent active coping strategy referred to four times by our informants was "avoidance" — of any situation or incident that might lead to hostility towards them, 
including staying away from places where they have experienced anti-Muslim sentiment. For example, Fatma told us that after such an experience she went out as little as possible out of fear that it would happen again. Ozan mentioned that he started avoiding large gatherings and parties after noticing that people acted anxious around him. One may wonder whether or not such an avoidance coping strategy is linked to what Antonio Gramsci (1971) has coined "cultural hegemony" where the dominant normative view and worldview of the majority are interiorized and come to be seen as the norm by the minorities who submit to it:

“There's this label that 'we' [Muslims] are the losers of the world, we don't have any power left. The power belongs to capitalism, the West and not with you [Muslims]. ( ... ) You don't have a voice and we can't defend ourselves in Belgium because bad Muslims exist, they are here. If I defend myself, they [Belgians] will say 'You speak for yourself and not for all Muslims. You are good but the others are bad'. (... )

Sometimes, the stigma is dangerous because people get upset and angry. (...) If you look at me like I am a criminal, I eventually will believe it and not everyone will try to prove you otherwise. Some people, when there is a crisis or when they get really angry, will become a criminal for real." (Ozan, 33)

An additional coping technique consists in adapting one's physical appearance and denying one's religious convictions by making statements about religion that are assumed to be in line with Western views, the better to blend in one's environment and avoid stigmatizing reactions.

"I don't wear a headscarf. I've been thinking about it for a long time because I would like to wear one-but I don't because it would limit my professional opportunities, it would just limit my chances of finding a good job." (Fatma, 24)

"I don't lie, but (... ) I say, for example, "Yes, I'm a Muslim, but I'm not religious". This defuses the situation somewhat." (Malik, 24)

\subsubsection{Passive Strategy}

Another way of dealing with racism or anti-Muslim prejudice is a passive approachsimply failing to react at all, as shown in the quotes below. This way of dealing with Islamophobia was mentioned eight times during the interviews.

"In such moments I often think 'It's better that I remain silent', but later on in bed I think 'THIS is what I should have said'." (Noor, 19)

"My parents are very strict in that area. They say to me 'Never react', they say 'Never react, always let those people have their way, Yara, you must not forget that they are more Belgian than you are'. But I am also Belgian, I was also born here, I was raised here, I am studying here, I am probably going to live here, I am going to have children here, and my children are going to live here and so on and so on, but they are still in their country. That's very stupid and that's very negative, I know, but you always have in the back of your mind: 'it is their country'." (Yara, 19)

Lack of reaction is often meant to defuse the situation. It can also strike one as being the only reasonable course of action. This coping strategy is different from suppression in that, when suppressing the incident, one is actively trying to deny it, while in the case of a passive strategy the incident is recognized but not reacted to.

According to Ines and Ozan, being confronted with racism and negative stereotyping on a regular basis can cause Muslims to turn away from Western values, as they simply feel rejected by society. In other words, their defense mechanism is to walk away, so to speak. Concern was expressed about the vulnerability of uprooted youngsters to radical beliefs and violent extremism.

Not only is there no reaction towards the victimizer, but in processing past situations the victim can blot out his or her experience of anti-Muslim prejudice. The reasons for this vary from shame to seeing no use in thinking about it to not wanting to worry or sadden 
one's family. For instance, Malik said that it was bad enough for him to have to experience it and that there was no point in burdening his family with it.

Depending on the situation the coping strategies described by young Muslim adults can be interchanged or combined to face hostile behaviours targeting their faith or appearance.

"Most of the time I regret not saying anything ... I always stay silent. I am the kind of
person who doesn't elaborate on such remarks because they are just not worth it."

What did you do when you became a victim of Islamophobia?

"I am a real family person. I am the youngest one in the house so nothing stays a secret. I immediately tell everything to my mom or my dad when things like that happen." (Meyra, 22)

\section{Conclusions}

The findings of this explorative investigation offered insights into the lived experiences of young Muslim college and university students and graduates in Flanders with respect to racism/anti-Muslim prejudice, taking into account gender, creed (strictly practicing, practicing, not practicing) and place of residence (urban versus rural area). We attempted to be as exhaustive as possible in presenting mechanisms that may be useful in dealing with anti-Muslim sentiment, the origins of anti-Muslim sentiment, and potential solutions based on the experiences of Muslim youth living in Flanders. Our in-depth interviews with 14 Flemish Muslims showed that they all have experienced anti-Muslim sentiment, albeit in different ways and with different frequencies. Several mediating factors were considered, such as the place of residence of the victimizer, the age of the victimizer, external religious signs, and the gender of the victim. We then looked at the ways in which our informants dealt with anti-Muslim prejudice. Based on this, and partly inspired by the literature, a typology was drawn with seven coping strategies: relativizing, avoidance, communication, suppression, conciliation, reaction and passive coping strategies.

This study pointed out two important findings which are challenging some of the basic assumptions in the academic literature and in political debates. First of all, we found out that Muslim students experience discriminatory practices not as something deeply rooted in "culture" or "cultural differences", but rather as attitudes stemming from prejudices based on external appearances. When looking at the occurrence of anti-Muslim sentiment, the literature shows greater emphasis on the religious and customary aspects of Islam, such as the contents of the Koran and their interpretation, than became apparent in our findings, where the focus was more on outward appearances and the stereotypical impressions people can have of individuals who "look" Muslim. This may be due to the residence of the informants: i.e., Flanders, a much narrower scope than in the literature.

Second, unlike other studies in the literature, this study focused on the rationales behind adopting different strategies for coping with anti-Muslim sentiments, shifting the focus from the outcomes of coping mechanisms to the intentions of the young Muslim in need of a coping mechanism. When focusing on the intentions behind the coping strategies, external influences on the outcomes of the strategies can be disregarded, which allows mental health practitioners and professionals in the field to adequately support those young Muslims when met with anti-Muslim sentiment. By mainly examining the intentions of the young Muslims, their coping mechanisms can be better understood, putting aside the external factors influencing the outcome of those coping mechanisms. These external factors include, but are not limited to, the communication skills of the victim, the openness for criticism of the aggressor and possible language barriers.

This research was limited by the size of the sample. It focused on the personal, subjective experiences of a few higher educated young Muslim adults living in a Western environment in Europe. Further research will need to focus on a more diverse set of education levels, ages and cultures. Also, the type of research-thematic analysis with semi-structured in-depth interviews - has its limitations (Boeije 2014), one "bias" being the "information bias". For example, it is possible that a "recall bias" occurred. After all, our 
interviews were conducted at the beginning of the Covid-19 crisis, when we were all in lockdown. At that time news about the SARS-CoV-2 virus dominated the media and the public debate.

Safety regulations were also tightened; there was an incentive to stay indoors and to practice "social distancing." As a result, situations in which anti-Muslim sentiment might manifest itself could not occur, and the memory of the "normal course of events" disappeared in the background. A post-Covid follow-up study may clarify this. In addition to the "recall bias," "social desirability" must also be taken into account when interpreting the research results. The informed consent form mentioned that the study was about Islamophobia so there is a good chance that the answers of the informants were coloured by prior knowledge of the research theme. To minimize this factor and to reassure the informants, it was stressed that there were no wrong answers. We also insisted on the fact that participation was in itself very useful, to prevent informants from answering in ways they thought might benefit the research. Owing to the Covid crisis some interviews had to be conducted by telephone, and it was apparent that informants felt more comfortable talking over the phone than in a face-to-face conversation. For this reason, telephone contact was chosen for the majority of subsequent interviews. Furthermore, the coding of the interviews has been done consistently and iteratively, thus minimizing researcher bias.

As indicated by Omlo (2015) the coping strategies are not mutually exclusive but complement each other. Characterizing them can contribute to a better understanding of the experiences of Muslims, and this, in turn, can help them deal with racism/antiMuslim sentiment. In addition, this understanding can, on the one hand, counteract the ignorance cited by the informants and, on the other hand, generate empathy among nonMuslims, bringing about a much needed mutual understanding in times of growing social polarization.

Building on this qualitative exploratory research, quantitative, preferably longitudinal, cross-country survey research is recommended, to quantify the findings and uncover potential cause-effect relationships. Therefore the present exploratory study will serve to initiate the deductive testing of the relative occurrence of the identified coping strategies on a broader scale, to form a guideline for policymakers, and to inspire follow-up research. These results may serve as guidelines for anti-discrimination and anti-racism policymaking and intervention models. Positive actions likely to counter prejudice-such as facilitating contact between Muslims and non-Muslims_can be put forward in policies. This must be done in an informed and well-considered way so as not to unduly emphasize differences between cultures, which might contribute to a further culturalization of the debate (Zemni 2009). Any type of government intervention can help defuse anti-Muslim sentiment, but it can just as easily exacerbate it (Kundnani 2014). Evidence-based policymaking and intervention programs can help overcome that risk.

Author Contributions: Conceptualization, A.D.N. and L.d.; methodology, A.D.N., L.d. and A.M.B.; validation, A.D.N., L.d. and A.M.-B.; formal analysis, A.D.N.; investigation, A.D.N. and L.d.; resources, A.D.N., L.d. and A.M.-B.; data curation, A.D.N.; writing—original draft preparation, A.D.N.; writing—review and editing, A.D.N., L.d. and A.M.-B.; visualization, A.D.N.; supervision, L.d.; project administration, L.d. and A.M.-B.; funding acquisition, L.d. and A.M.-B. All authors have read and agreed to the published version of the manuscript.

Funding: The project is funded by the Social Sciences and Humanities Research Council of Canada (890-2018-0016).

Institutional Review Board Statement: The study was conducted according to the guidelines of the Declaration of Helsinki, and approved by the Institutional Review Board (or Ethics Committee) of Laval University (protocol code 2019-155/ 29-07-2019).

Informed Consent Statement: Informed consent was obtained from all subjects involved in the study.

Data Availability Statement: The data presented in this study are available on request from the corresponding author. The data are not publicly available due to privacy concerns. 
Acknowledgments: We would like to express our deepest gratitude to our interviewees. Without their trust and willingness to cooperate, we would not have been able to carry out this investigation. We also extend our thanks to the reviewers of our manuscript for their valuable input.

Conflicts of Interest: The authors declare no conflict of interest.

\section{Appendix A. Overview of Coded Themes}

\begin{tabular}{|c|c|}
\hline Code & Subcodes First Coding \\
\hline Experience with anti-Muslim sentiment & $\begin{array}{l}\text { - } \text { Rejection or contempt on the basis of religious identity } \\
\text { - } \quad \text { Image non-Muslims } \\
\text { - } \\
\text { - } \quad \text { Behaviour non-Muslim Belgians towards Muslims } \\
\text { - } \\
\text { Anstim of hatred or discrimination because of being a Muslim } \\
\text { discrimination } \\
\text { - } \\
\text { Answer to the statement about Islam as a threat to Belgian } \\
\text { - } \\
\text { - Answer to the statement about Muslims abusing generosity } \\
\text { Answer to the statement about Muslims experiencing racism }\end{array}$ \\
\hline Causes of anti-Muslim sentiment & 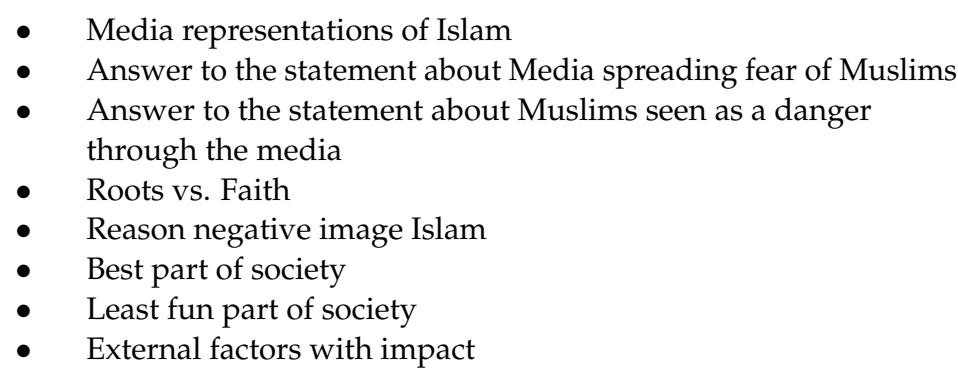 \\
\hline
\end{tabular}

- $\quad$ Dealing with hatred, discrimination or benefits because of being a Muslim

- $\quad$ Active coping strategies

Coping mechanisms in the face of anti-Muslim sentiment

- $\quad$ Passive coping strategies

- Relativizing

- Internal processing

- External processing

- $\quad$ Show understanding

Fighting anti-Muslim sentiment

Demographic data
- Contact

- Media

- Education

- Politics

- Knowledge of languages

- Job

- Gender

- Current educational level

- Current status in Belgium

- Age

- Definition as Muslim

- Country of birth

- Country of birth parents 


\section{References}

Aziz, Rachida. 2017. Nobody Will Sleep Here Tonight. Antwerp: Epo.

Aziza, Margari. 2015. Strategies for Coping with Islamophobia. March 27. Available online: http://www.altmuslimah.com/2015/03/ strategies-coping-islamophobia/ (accessed on 10 March 2020).

Bloom, Pazit Ben-Nun, Shaul Kimhi, Shani Fachter, Michal Shamai, and Daphna Canetti. 2019. Coping with Moral Threat: Moral Judgment amid War on Terror. Journal of Conflict Resolution 64: 231-60. [CrossRef]

Boeije, Hennie R. 2014. Analysing in Qualitative Research. The Hague: Boom Lemma.

Branscombe, Nyla R., Michael Thomas Schmitt, and Richard Harvey. 1999. Perceiving pervasive discrimination among African Americans: Implications for group identification and well-being. Journal of Personality and Social Psychology 77: 135-49. [CrossRef]

Brondolo, Elizabeth, Ricardo Rieppi, Stephanie A. Erickson, Emilia Bagiella, Peter A. Shapiro, Paula McKinley, and Richard P. Sloan. 2003. Hostility, interpersonal interactions, and ambulatory blood pressure. Psychosomatic Medicine 65: 1003-11. [CrossRef] [PubMed]

Carr, James. 2018. Experiences of Islamophobia: Living with Racism in the Neoliberal Era, 1st ed. Routledge Research in Race and Ethnicity. London: Routledge.

CTID (Het Collectief tegen Islamofobie en Discriminatie). 2017. Islamophobia Acknowledging, Recognising and Combating! September. Available online: https:/ / emcemo.nl/wp-content/uploads/2017/12/Islamofobie_herkennenbestrijden.pdf (accessed on 10 March 2020).

d'Haenens, Leen, Willem Joris, and François Heinderyckx, eds. 2019. Images of Immigrants and Refugees in Western Europe. Media Representations, Public Opinion and Refugees' Experiences. Leuven: Leuven University Press.

De Koning, Martijn. 2019. 5 Myths about Islamophobia. Antwerp: Yunus Publishing.

De Ridder, Kathleen. 2010. The White Media. Tielt: Lannoo.

DeJonckheere, Melissa, and Lisa. M. Vaughn. 2019. Semistructured interviewing in primary care research: A balance of relationship and rigour. Family Medicine and Community Health 7: e000057. [CrossRef]

DiCicco-Bloom, Barbara, and Benjamin F. Crabtree. 2006. The qualitative research interview. Medical Education 40: 314-21. [CrossRef] [PubMed]

Easat-Daas, Amina. 2019. The Gendered Dimension of Islamophobia in Belgium. In The Routledge International Handbook of Islamophobia, 1st ed. London: Routledge, pp. 123-34. [CrossRef]

Field, Clive D. 2007. Islamophobia in contemporary Britain: The evidence of the opinion Polls, 1988-2006. Islam and Christian-Muslim Relations 18: 447-77. [CrossRef]

Fischer, Ann R., and Christina M. Shaw. 1999. African Americans' mental health and perceptions of racist discrimination: The moderating effects of racial socialization experiences and self-esteem. Journal of Counseling Psychology 46: 395-407. [CrossRef]

Foner, Nancy, and Richard Alba. 2008. Immigrant religion in the U.S. and Western Europe: Bridge or barrier to inclusion? International Migration Review 42: 360-92. [CrossRef]

Gramsci, Antonio. 1971. Selections from the Prison Notebooks. Translated and Edited by Quintin Hoare and Geoffrey Nowell Smith. New York: International Publishers.

Green, Todd. 2019. Islamophobia. Oxford Research Encyclopedia of Religion. [CrossRef]

Halliday, Fred. 1999. 'Islamophobia' reconsidered. Ethnic and Racial Studies 22: 892-902. [CrossRef]

Heatherton, Todd F. 2003. The Social Psychology of Stigma. New York: Guilford Publications.

Hertogen, Jan. 2017. Non-Profit Data. December 1. Available online: http:/ /www.npdata.be/ (accessed on 7 November 2020).

Ichau, Elke, and Leen d'Haenens. 2016. The representation of Islam and Muslims in Flemish TV news. In Representations of Islam in the News, A Cross-Cultural Analysis. Edited by Stefan Mertens and Hedwig De Smaele. Lanham: Lexington Books, pp. 91-108.

Jasinskaja-Lathi, Inga, Karmela Liebkind, and Erling Solheim. 2008. To identify or not to identify? National disidentification as an alternative reaction to perceived ethnic discrimination. Applied Psychology 58: 105-28. [CrossRef]

Kundnani, Arun. 2014. The Muslims Are Coming. London: Verso.

Kunst, Jonas R., Hajra Tajamal, David L. Sam, and Pål Ulleberg. 2012. Coping with Islamophobia: The effects of religious stigma on Muslim minorities' identity formation. International Journal of Intercultural Relations 36: 518-32. [CrossRef]

Kunst, Jonas R., David L. Sam, and Pål Ulleberg. 2013. Perceived Islamophobia: Scale development and validation. International Journal of Intercultural Relations 37: 225-37. [CrossRef]

Kuzmanić, Marja. 2009. Validity in Qualitative Research: Interview and the Appearance of Truth through Dialogue. Psihološka Obzorja 18: 39-50.

Major, Brenda, and Laurie T. O’Brien. 2005. The social psychology of stigma. Annual Review of Psychology 56: 393-421. [CrossRef] [PubMed]

Major, Brenda, Wendy J. Quinton, and Shannon K. McCoy. 2002. Antecedents and consequences of attributions to discrimination: Theoretical and empirical advances. Advances in Experimental Social Psychology 34: 251-330.

Martín-Muñoz, Gema. 2010. Unconscious Islamophobia. Human Architecture: Journal of the Sociology of Self-Knowledge 8: 21-28.

Marton, Ference. 1986. Phenomenography-A research approach investigating different understandings of reality. Journal of Thought 21: $28-49$. 
Mekki-Berrada, Abdelwahed. 2019. Islamophobie viriliste et radicalisation islamophobe: Prolégomènes à une réhabilitation de la notion d'islamophobie. Religiologiques, 5-49. Available online: https://religiologiques.uqam.ca/no39/39_005-049_Mekki-Berrada.pdf (accessed on 4 August 2020).

Mekki-Berrada, Abdelwahed, and Stephen L. Schensul. 2018. De la " complicité » des imams dans la promotion de l'équité de genre à Mumbai, en Inde. Anthropologie et Sociétés 42: 227-52. [CrossRef]

Najib, Kawtar, and Peter Hopkins. 2019. Veiled Muslim women's strategies in response to Islamophobia in Paris. Political Geography 73: 103-11. [CrossRef]

Omlo, Juriaan. 2015. How Migrants Deal with Discrimination. Radicalise, Withdraw or Tolerate? Available online: http: //www.republiekallochtonie.nl/blog/achtergronden/hoe-migranten-omgaan-met-discriminatie-radicaliseren-terugtrekkenof-verdragen (accessed on 10 March 2020).

Palaganas, Erlinda C., Marian C. Sanchez, Visitacion P. Molintas, and Ruel D. Caricativo. 2017. Reflexivity in qualitative research: A journey of learning. The Qualitative Report 22: 426-38. Available online: https://nsuworks.nova.edu/tqr/vol22/iss2/5 (accessed on 2 April 2020).

Pew Research Center. 2017. Europe's Growing Muslim Population. November. Available online: https://www.pewforum.org/2017/1 1/29/europes-growing-muslim-population / (accessed on 12 March 2020).

Rahbari, Ladan. 2020. When gender turns right: Racializing Islam and femonationalism in online political discourses in Belgium. Contemporary Politics 27: 41-57. [CrossRef]

Roose, Henk. 2017. Methodology of Social Science: An introduction. Amsterdam: Amsterdam University Press.

Rousseau, Cécile, Taïeb Ferradji, Abdelwahed Mekki-Berrada, and Uzma Jamil. 2013. North African Muslim immigrant families in Canada giving meaning to and coping with the war on terror. Journal of Immigrant $\mathcal{E}$ Refugee Studies 11: 136-56. [CrossRef]

Savin-Baden, Maggi, and Claire Howell Major. 2013. Qualitative Research: The Essential Guide to Theory and Practice. London: Routledge. Sayyid, Salman, and Abdoolkarim Vakil. 2010. Thinking Through Islamophobia. London: Hurst.

Spruyt, Bram, and Mark Elchardus. 2012. Violence, fear of crime, and Islam scepticism. International Review of Sociology 22: 552-64. [CrossRef]

Steele, Claude M., Steven J. Spencer, and Joshua Aronson. 2002. Contending with group image: The psychology of stereotype and social identity threat. Advances in Experimental Social Psychology 34: 379-440.

Taras, Raymond. 2013. 'Islamophobia never stands still': Race, religion, and culture. Ethnic and Racial Studies 36: 417-33. [CrossRef]

Verkuyten, Maykel, and Ali Aslan Yildiz. 2007. National (Dis)identification and ethnic and religious identity: A study among Turkish-Dutch Muslims. Personality and Social Psychology Bulletin 33: 1448-62. [CrossRef]

Vrancken, Peter H. 2017. Non-Congenital Brain Injuries in Adults. Houten: Bohn Stafleu van Loghum.

Abu-Ras, Wahiba, Ali Gheith, and Francine Cournos. 2008. The Imam's role in mental health promotion: A study at 22 mosques in New York City Muslim community. Journal of Muslim Mental Health 3: 155-76. [CrossRef]

Williams, David R., Harold W. Neighbors, and James S. Jackson. 2003. Racial/ethnic discrimination and health: Findings from community studies. American Journal of Public Health 93: 200-8. [CrossRef]

Zemni, Sami. 2009. The Islamdebate. Berchem: EPO.

Zemni, Sami. 2011. The shaping of Islam and Islamophobia in Belgium. Race E Class 53: 28-44. [CrossRef] 